\title{
Cavernas e o desenvolvimento de práticas no estudo de ciências: um estudo com alunos do sexto ano escolar
}

Marconi Souza Silva

Rodrigo Lopes Ferreira

Roberta Correa Damasceno

\begin{abstract}
Resumo
O objetivo do presente trabalho foi de promover uma conscientização ambiental junto a alunos da educação básica sobre a importância da prática de espeleoturismo consciente e características da fauna de cavernas, e em contrapartida, avaliar a capacidade informativa de uma cartilha ilustrada. Através do uso de questionários percebeu-se que apesar dos alunos residirem em uma região com muitas cavernas, a escola não utiliza visitas a cavernas como uma prática pedagógica. A ausência de práticas pedagógicas e experiências informais podem justificar o pouco conhecimento que os alunos têm sobre as cavernas. Após a aplicação de cartilha ilustrada, novas percepções sobre o ambiente de cavernas foram construídas. A cartilha mostrou ser um importante instrumento de mudança de percepção, para o publico alvo em questão. Assim, a mesma é recomendada como ferramenta de promoção de mudança de percepção sobre temas no ensino de ciências e Educação ambiental.
\end{abstract}

Palavras-chaves: Cartilhas; Cavernas; Educação ambiental.

\begin{abstract}
The aim of this study was to promote environmental advices to students of basic education about the importance of practicing a tenable spelunking and characteristics of the of cave fauna, and in return, evaluate the capacity to inform of an illustrated booklet. Through the use of questions was noticed that although the students reside in an area with caves, the school does not use visits to caves as a teaching practice. The lack of teaching practices and informal experiences can justify the little knowledge that students have about caves. After applying illustrated booklet, new insights about the cave environments were built. The booklet can be an important instrument to change perceptions, for the audience in question. Thus, it is recommended as a tool to be use in topics like science and environmental education.
\end{abstract}

Keywords: Pamphlets; Caves; environmental education. 


\section{1- Introdução}

A formação do indivíduo em ciências contribui para uma melhor compreensão e aprofundamento das explicações referentes a conceitos e processos relacionados a temas que envolvem seres vivos e na tomadas de decisões individuais ou coletivas relacionadas à ética e responsabilidades econômicas, sociais e ambientais. Neste sentido a Educação Ambiental surge com um importante processo de criação e mudança de percepção no intuito de transmitir conhecimentos, valores, habilidades, experiências que capacitam indivíduos e comunidade a agir frente a questões ambientais (Dias, 2001; Krasilchik, 2004).

A educação ambiental assume, de maneira crescente, a forma de um processo intelectual ativo, baseado no diálogo e interação em constante processo de recriação e reinterpretação de informações, conceitos e significados, que se originam do aprendizado em sala de aula e da experiência pessoal. Aponta para propostas pedagógicas centradas na conscientização, mudança de comportamento, desenvolvimento de competências, capacidade de avaliação e participação dos educadores (Reigota, 1998; Jacobi, 2003).

Neste sentido, cartilhas e folhetos impressos são úteis para o trabalho educativo uma vez que informam e reforçam mensagens aprendidas através de outros veículos de comunicação. Além disto, fornecem informações adicionais e estimulam a adoção de práticas recomendadas (Lencastre, 1986; Krasilchik, 2004; Santos 2005). Um grande número de folhetos e cartilhas está disponível na internet, órgãos do governo e ONGs e abordam diferentes aspectos da questão ambiental como erosão, água, proteção de nascentes, reciclagem, lixo, agenda 21 dentre outros (IBAMA, 2013; IPÊ, 2013; GRAFEN, 2013; CDRC, 2013; Cl, 2013; ECOAR, 2013). A produção deste material foi incrementada, após a proposta da reforma de ensino que coloca a Educação Ambiental como um tema transversal, indicado para as séries iniciais do ensino fundamental, e que deve ser abordado por um processo de inovação educativa que envolve tanto o professor quanto os alunos e a comunidade (Maia-Barbosa et al 2004).

Entretanto, mesmo com uma audiência com capacidade de leitura, o material impresso por si, não conduzirá a comportamentos diferenciados, especialmente se vier carregado de jargões e termos técnicos, ilustrações pobres, frases longas, sentenças complicadas, mal diagramadas e sem um planejamento que estimule a leitura (Ward, 1982).

A principal função de se trabalhar na escola o tema Meio Ambiente, de acordo com os temas transversais (MEC, 1998) é a de ajudar na formação de cidadãos capazes de decidir em questões socioambientais comprometendo-se com o bem-estar individual e da sociedade. Para que isso ocorra, é necessário informar, trabalhar com atitudes e formação de valores, com o ensino e a aprendizagem, e experiências formais e não formais de educadores e educandos.

Um dos espaços passíveis de serem explorados para um trabalho de ensino-aprendizagem são as cavernas. Estas foram um dos primeiros espaços utilizados pelos homens pré-históricos 
como moradia, locais de socialização, expressão de sua arte e comunicação. Na sociedade atual as cavernas são, para alguns, uma interessante e peculiar paisagem a ser visitada e contemplada e despertam sentimentos de fascínios e sensibilidade frente a fragilidade das formas. Assim, tem ocorrido um aumento significativo da procura e visitação de cavernas, no Brasil e no mundo (Figueiredo, 1998; Marra, 2001; Cigna \& Forti, 2013). Atualmente, o uso turístico, uso religioso e em cuidados de saúde são as principais atividades que podem gerar enormes fluxos turísticos no mundo (Cigna \& Forti, 2013). No Brasil existem importantes cavernas que recebem turismo em massa e onde as escolas realizam om visitas guiadas cpráticas pedagógicas, nos estados de Santa Catarina, Paraná, São Paulo, Minas Gerais, Espirito Santo, Bahia, Rio Grande do Norte, Ceará, Goiás, Mato Grosso, Mato Grosso do Sul (Marra, 2001).

As escolas são importantes veículos na divulgação do turismo em cavernas, e a importância das cavernas nas práticas pedagógicas mostra-se abrangente, para os ensinos Fundamental, Médio e Superior. Morgado e colaboradores (1996) citam disciplinas dos ensinos fundamental e médio, e associações que podem ser extraídas do ambiente cavernícola relativas a tais disciplinas. Dentre elas destaca-se a biologia, química, geografia, física, etc. Entretanto, as possibilidades de uso do ambiente de cavernas em práticas de ciências é ampla e pode ser facilitada, pelo fato das cavernas despertarem curiosidades.

Incentivar uma prática de espeleoturismo na educação básica que busque um compromisso maior com a preservação do ambiente, da cultura e com os devidos benefícios sociais é relevante, contudo é possível afirmar que não é tarefa, sobretudo, por que mesmo em locais onde a visitação é controlada, os diversos impactos decorrentes do turismo continuam a existir. Alguns autores arriscam propor uma definição nesse sentido, apresentando o espeleoturismo como um segmento turístico que busca atingir de forma equilibrada a conservação das cavidades naturais, a conscientização e satisfação de todos os envolvidos no processo turístico e o desenvolvimento econômico local. Utiliza para tanto o patrimônio espeleológico, aproveitando as particularidades do ambiente por meio de propostas de diferenciação mercadológica (Lobo, 2009; Cigna \& Forti, 2013).

Baseando-se na teoria de aprendizagem de Asubel, os conteúdos e informações adquiridas e a maneira como esses se organizam na mente de um indivíduo (estrutura cognitiva) podem depender de conceitos ou ideias pré-existentes as quais funcionam como "pontos de ancoragem", para que novas informações possam se integrar e facilitar a aprendizagem. Nesta linha de pensamento a aprendizagem significativa contrasta com a aprendizagem mecânica, uma vez que, na primeira, toda nova informação interage com estes "pontos de ancoragem" (chamados de subsunçor) e se fixa com mais facilidade e por um tempo mais longo, ao contrario da aprendizagem mecânica, onde a ausência de um subsunçor faz com que a informação seja armazenada de forma efêmera (Pelizzari et al 2002; Darroz et al. 2013). 
O presente estudo teve como objetivo enriquecer a temática de conscientização ambiental junto a alunos da educação básica sobre a importância da prática de espeleoturismo consciente e avaliar a capacidade de informação de uma cartilha ilustrada, numa dinâmica de aprendizagem significativa (sem a necessidade de decorar informações), que aborda conceitos básicos relacionados ao tema biologia, usos e conservação de cavernas.

\section{2- Material e Método}

\subsection{Local de Estudo}

O presente trabalho foi realizado com 31 alunos do sexto ano de escolaridade nas aulas de Ciências. A escola está localizada no município de Ingai, Sul de Minas Gerais, próximo de uma área tradicionalmente espeleoturística e com cavernas quartzíticas localizadas nos municípios de Carrancas, São Tomé, Luminárias.

\subsection{Procedimentos}

Para explicitar conceitos básicos relacionados ao tema biologia e conservação de cavernas foi utilizada uma cartilha/folheto (Ferreira et al 2008). A cartilha ilustrada traz ludicamente informações das características, físicas, tróficas e da fauna de cavernas. Representantes de animais que frequentemente ocorrem nas cavernas são usados como personagens e relatam alterações que acontecem nestes ambientes em função da atividade humana e as prováveis consequências destas alterações para as cavernas. Os impactos mostrados correspondem àqueles frequentemente observados nas cavernas (e seu entorno). Ao final são apresentadas soluções para as alterações ambientais, mostrando que é possível conciliar a exploração com a conservação das cavernas. A cartilha apresenta também atividades de jogos e ilustrações para colorir, que têm como objetivos divertir e complementar a parte conceitual sobre ambientes de cavernas. Versões similares à cartilha ilustrada, que foi empregada neste trabalho, são descritas por outros pesquisadores como "gibis", "história em quadrinhos", etc.

Para avaliar a capacidade de informação temporária da cartilha ilustrada, foram realizados os seguintes passos:

(1) Seleção arbitrária de uma turma de alunos do sexto ano de escolaridade com idade em torno de 11 anos. (2) Aplicação de um questionário com 6 questões abertas que procurou avaliar o conhecimento informal prévio dos alunos sobre biologia e conservação de cavernas (Castro \& Bejarano 2013), (3) Disponibilização aos alunos da cartilha informativa sobre biologia e conservação de cavernas (Ferreira et al 2008). (4) Dois dias após a disponibilização da cartilha, aplicação surpresa do mesmo questionário com as mesmas 6 questões abertas, no intuito de avaliar mudança de percepção, mesmo que temporária, frente conhecimento informal dos alunos sobre biologia de cavernas. 
O questionário continha as seguintes questões:

(1) Você já visitou uma caverna?; (2) Como é o interior de uma caverna?; (3) Quais animais podem ser encontrados em uma caverna?; (4) Qual o alimento dos animais que vivem em uma caverna? (5) Quais cuidados devemos tomar para não prejudicar os animais que vivem nas cavernas?; (6) Que medidas você tomaria para preservar os animais que vivem nas cavernas?

Em nenhuma das ocasiões foi permitida a consulta a cartilha.

\subsection{Análises de Dados}

Os dados foram analisados utilizando-se o programa Excel 2007. Este programa possibilitou a categorização dos dados durante o seu processamento. As respostas categorizadas foram analisadas segundo sua freqüência, referindo-se a cada pergunta, sendo estas não mutuamente exclusivas.

Para garantir a privacidade dos participantes os questionários não foram nomeados, mas, identificados com códigos numéricos. Apenas os pesquisadores tiveram acesso aos questionários, que serão guardados por cinco anos e posteriormente incinerados. Os participantes da pesquisa poderiam desistir de sua participação a qualquer momento, mesmo depois de respondido o questionário, devendo o questionário ser devolvido ao participante, sem qualquer prejuízo a este. O projeto foi devidamente cadastrado na Comissão Nacional de Ética em Pesquisa (CONEP), Conselho Nacional de Saúde, Ministério da Saúde (folha de rosto para pesquisa envolvendo seres humanos № 256315), e autorizado pelo comitê de ética do Centro Universitário de Lavras (UNILAVRAS).

\section{3- Resultados}

De acordo com os resultados obtidos através dos questionários observou-se a pequena vivência dos alunos em relação ao tema cavernas e maior clareza e "veracidade" nas respostas obtidas após a leitura da cartilha (figura 1). De acordo com a pergunta, "Você já visitou uma caverna?" verifica-se que apesar da presença de cavernas na região a grande maioria dos entrevistados (77\%) nunca visitou uma caverna (figura1). Houve discrepâncias no número de entrevistados antes (30 alunos) e depois ( 25 alunos) da leitura da cartilha devido à ausência de alguns alunos. Alguns alunos (10\%) não responderam à questão 1 (figura 1 ). 


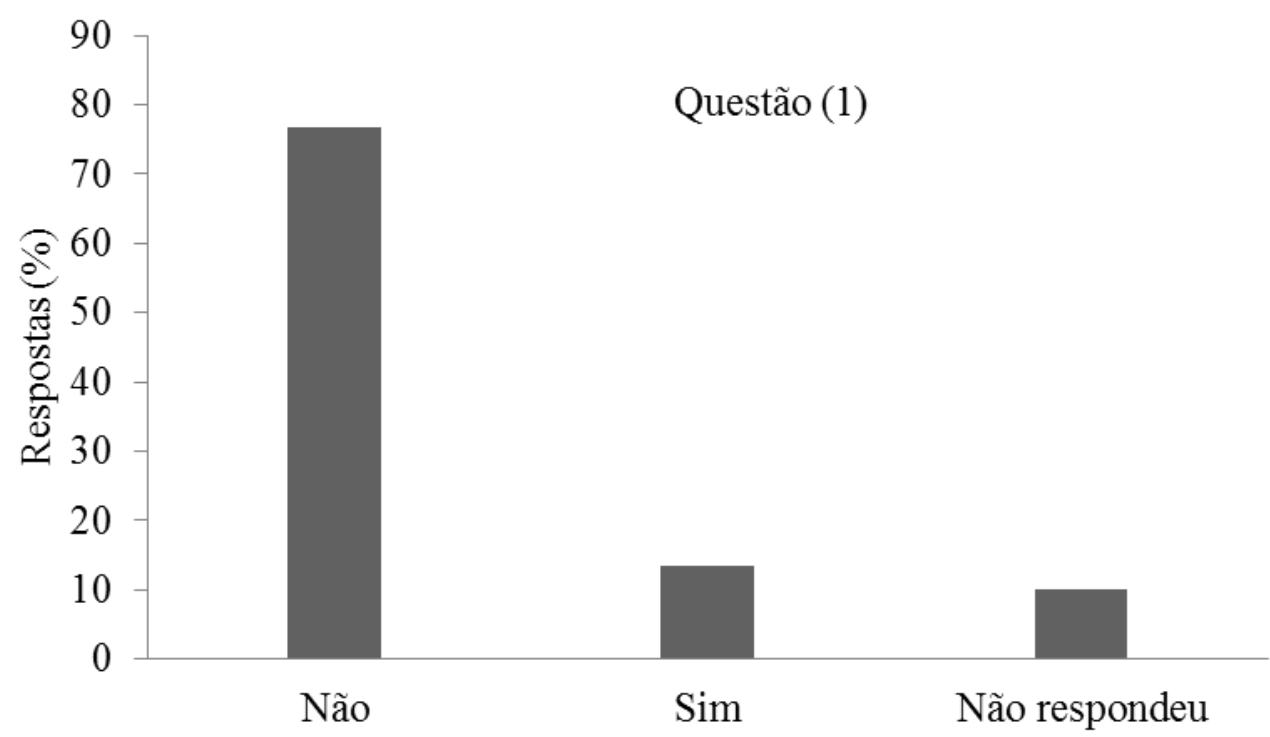

Figura 1. Porcentagem de alunos do sexto ano que não tem uma vivência prática de visita a cavernas. (1) Você já visitou uma caverna?

As respostas construídas em relação à segunda pergunta, "Como é o interior de uma caverna?" antes da leitura da cartilha, foram muito diversificadas e baseadas principalmente em elementos informais (figura 2A). A resposta "ainda não visitei" foi predominante. Entretanto, embora a maioria dos alunos ainda não tivesse visitado cavernas, os mesmos utilizam o conhecimento informal e o imaginário sobre cavernas, tendo arriscado uma resposta. As categorias de respostas após a leitura da cartilha se tornaram mais homogêneas e tendo maior frequência de respostas relacionadas à percepção da escuridão permanente (44\% dos alunos) destes ambientes (figura 2B). 

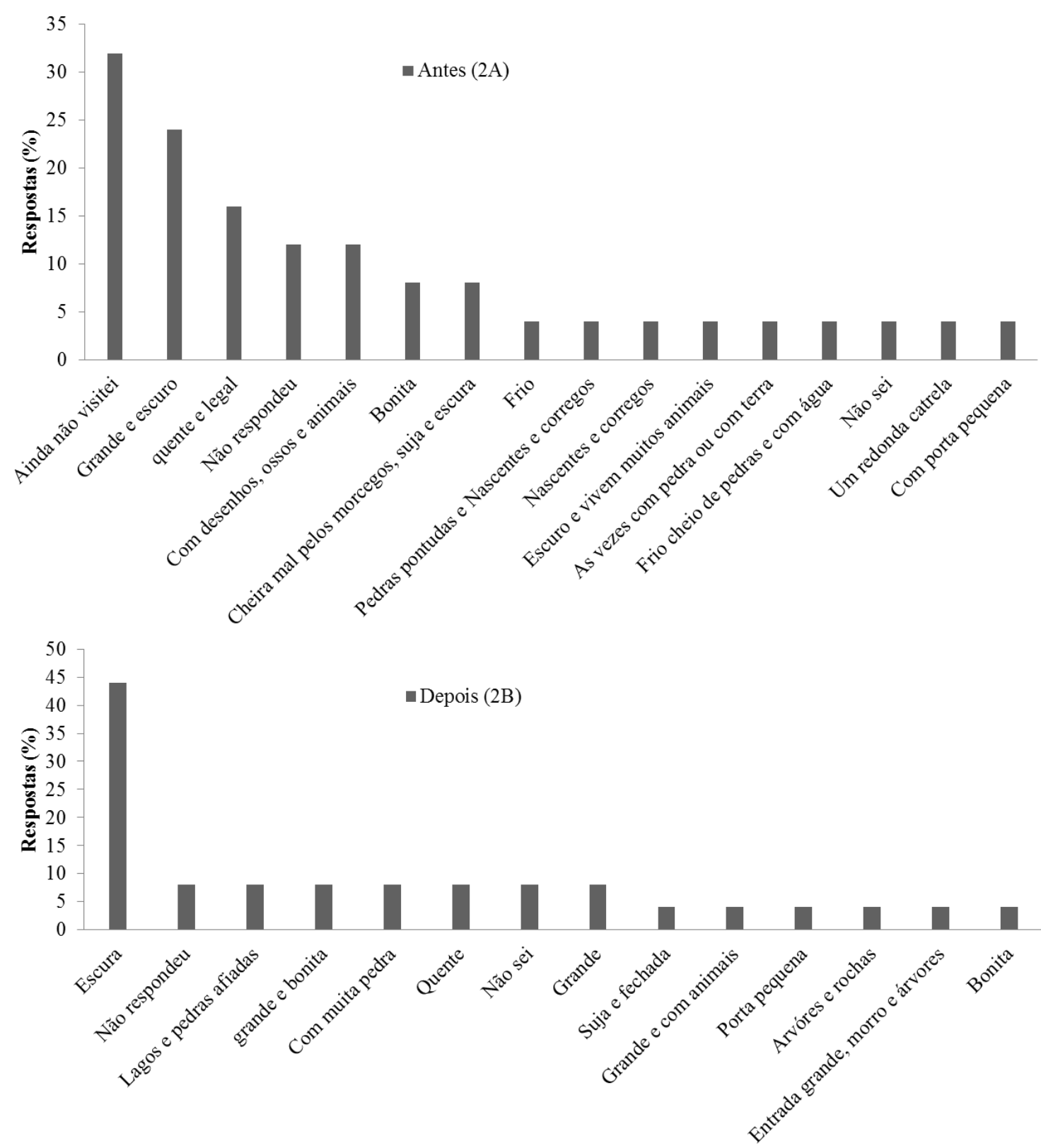

Figura 2. Categorias de respostas construídas com conhecimento informal (antes) e formal (depois), pelos alunos do sexto ano, sobre o ambiente de cavernas antes e após a leitura de uma cartilha informativa. (2) Como é o interior de uma caverna?

Em relação às respostas obtidas sobre a terceira questão "Quais animais podem ser encontrados em uma caverna?" evidenciou-se que as respostas obtidas antes da leitura da cartilha também foram diversificadas, citando animais frequentes em cavernas como morcegos (83\% dos alunos) e aqueles que geralmente não ocorrem nas cavernas do Brasil, como ursos (figura 3A). A 
citação de ursos pode, provavelmente, advir de informações adquiridas em desenhos apresentados pela mídia televisiva que apresentam cavernas como locais de morada destes animais. Outros animais de cavernas como aranhas e insetos também foram citados. Após a leitura da cartilha, as respostas à esta pergunta também foram diversificadas, mas baseadas nas informações contidas na cartilha. Os alunos citam morcegos (92\%), mariposas (52\%) e grilos (48\%) como animais de maior frequência em cavernas brasileiras (Figura 3B).
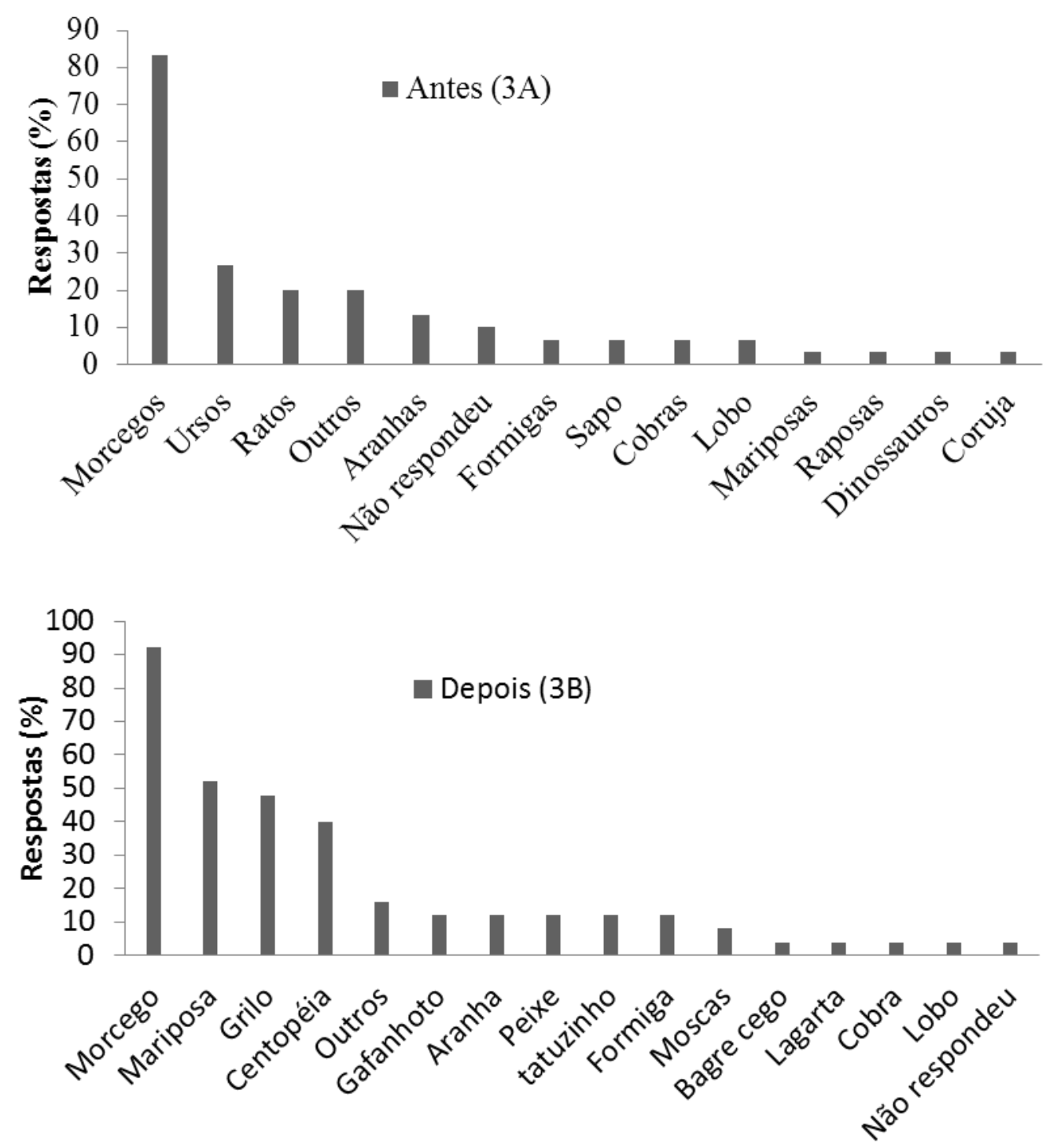

Figura 3. Categorias de respostas construídas com conhecimento informal (antes) e formal (depois), pelos alunos do sexto ano, sobre animais de cavernas antes e após a leitura de uma cartilha informativa.

(3) Quais animais podem ser encontrados em uma caverna?

$\mathrm{Na}$ construção das respostas para quarta questão "qual o alimento dos animais que vivem em uma caverna?", a resposta de maior frequência (48\%) foi o sangue (Figura 4A). Como esperado, 
isto provavelmente deve estar relacionado à citação de morcegos como habitante de caverna na questão anterior (Figura 3A e B). Vinte por cento dos alunos não responderam a esta pergunta.
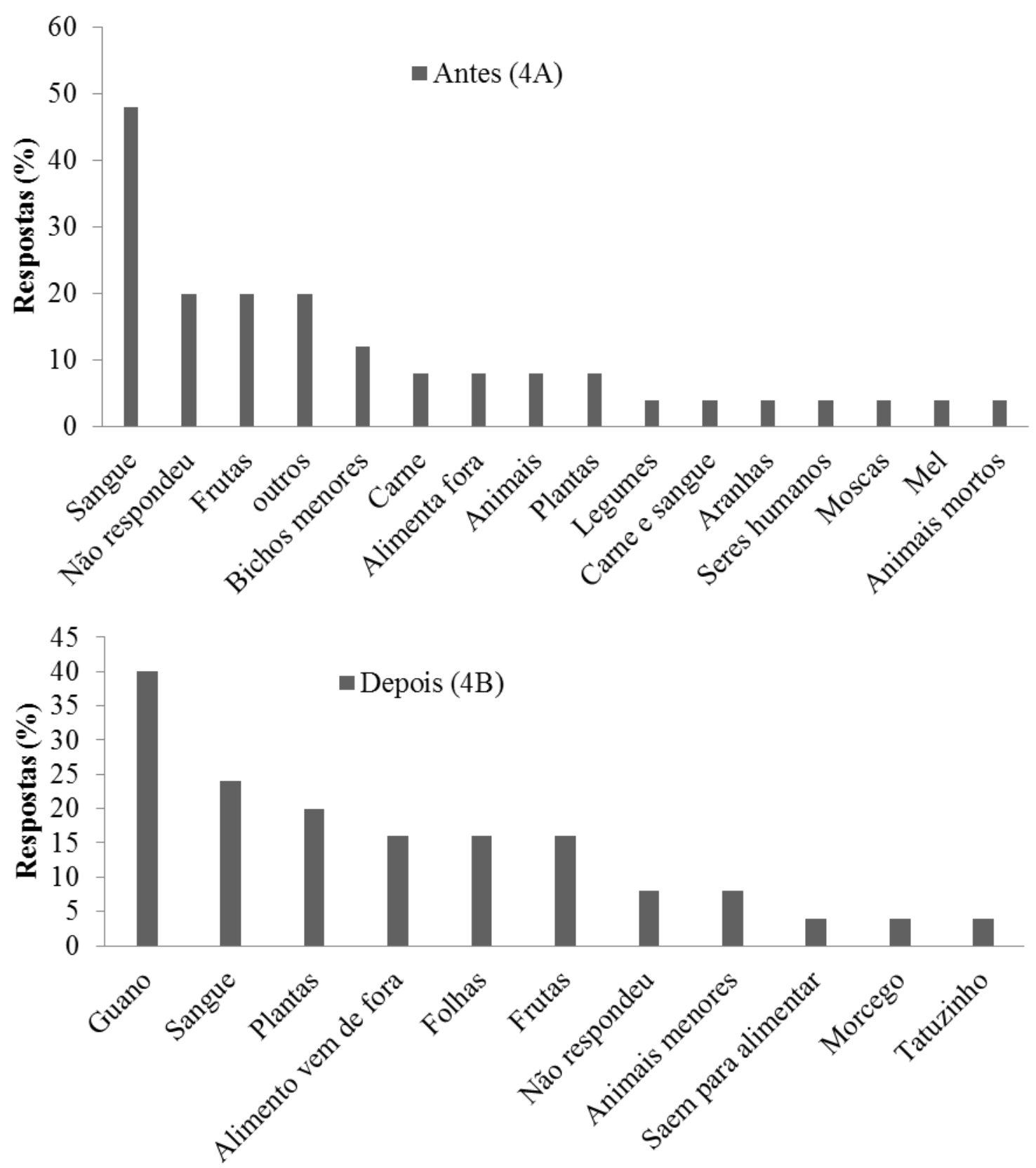

Figura 4. Categorias de respostas construídas com conhecimento informal (antes) e formal (depois), pelos alunos do sexto ano, sobre animais de cavernas antes e após a leitura de uma cartilha informativa.

(4) Qual o alimento dos animais que vivem em uma caverna? 
Após a leitura da cartilha, as respostas construídas para a questão também se baseiam em grande parte nas informações da cartilha (figura 4B). Neste caso, os alimentos mais citados foram guano (40\%), sangue (24\%), plantas (20\%) e alimentos que vêm de fora (16\%). O guano com alimento para os habitantes de caverna não havia sido citado antes da leitura da cartilha (Figura 4 A). A porcentagem de não respostas para esta questão caiu de $20 \%$ antes da leitura da cartilha, para $8 \%$ após a leitura da cartilha (Figura 4 A e B).

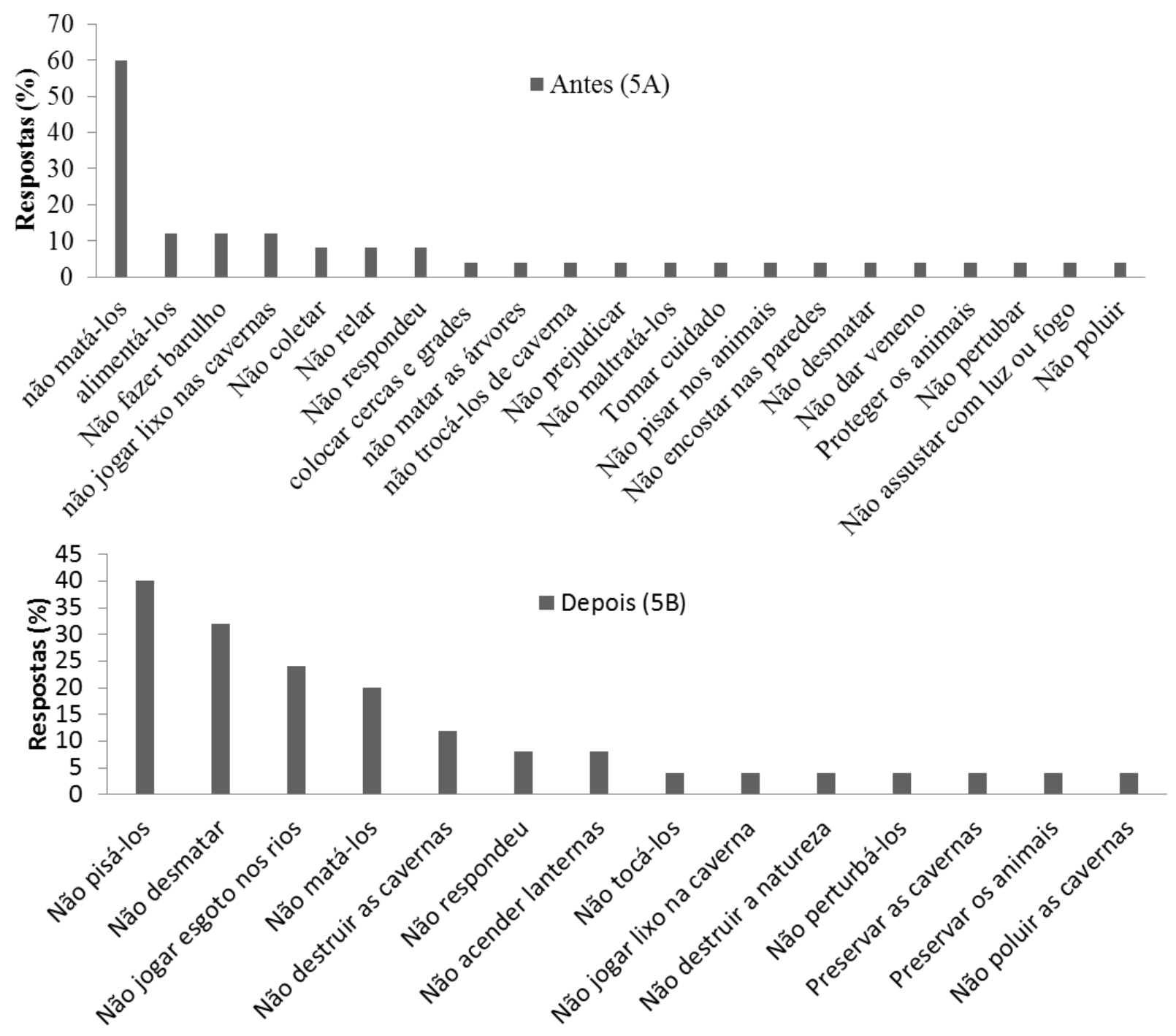

Figura 5. Categorias de respostas construídas com conhecimento informal (antes) e formal (depois), pelos alunos do sexto ano, sobre o alimento de animais de cavernas. (5) Quais cuidados deveram tomar para não prejudicar os animais que vivem nas cavernas?

As respostas mais freqüentes, construídas antes da leitura da cartilha para a quinta pergunta "Quais cuidados devemos tomar para não prejudicar os animais que vivem nas cavernas?" 
foram não matar (60\%) e alimentá-los (12\%) (figura 5A). Neste caso foi claro que os alunos entendem que deve-se manter os animais vivos, mas não citam quais alterações ambientais podem causar a morte dos mesmos (poluição, desmatamento, fogo, caça, dentre outros). Entretanto, após a leitura da cartilha, as respostas elaboradas para a mesma questão citam estes impactos e indicam que os mesmos são danosos aos animais de cavernas (figura 5B). As maiores frequências de categorias de respostas foram não pisá-los (40\%), não desmatar (32\%) e não jogar esgoto nos rios (24\%) (Figura 5B).
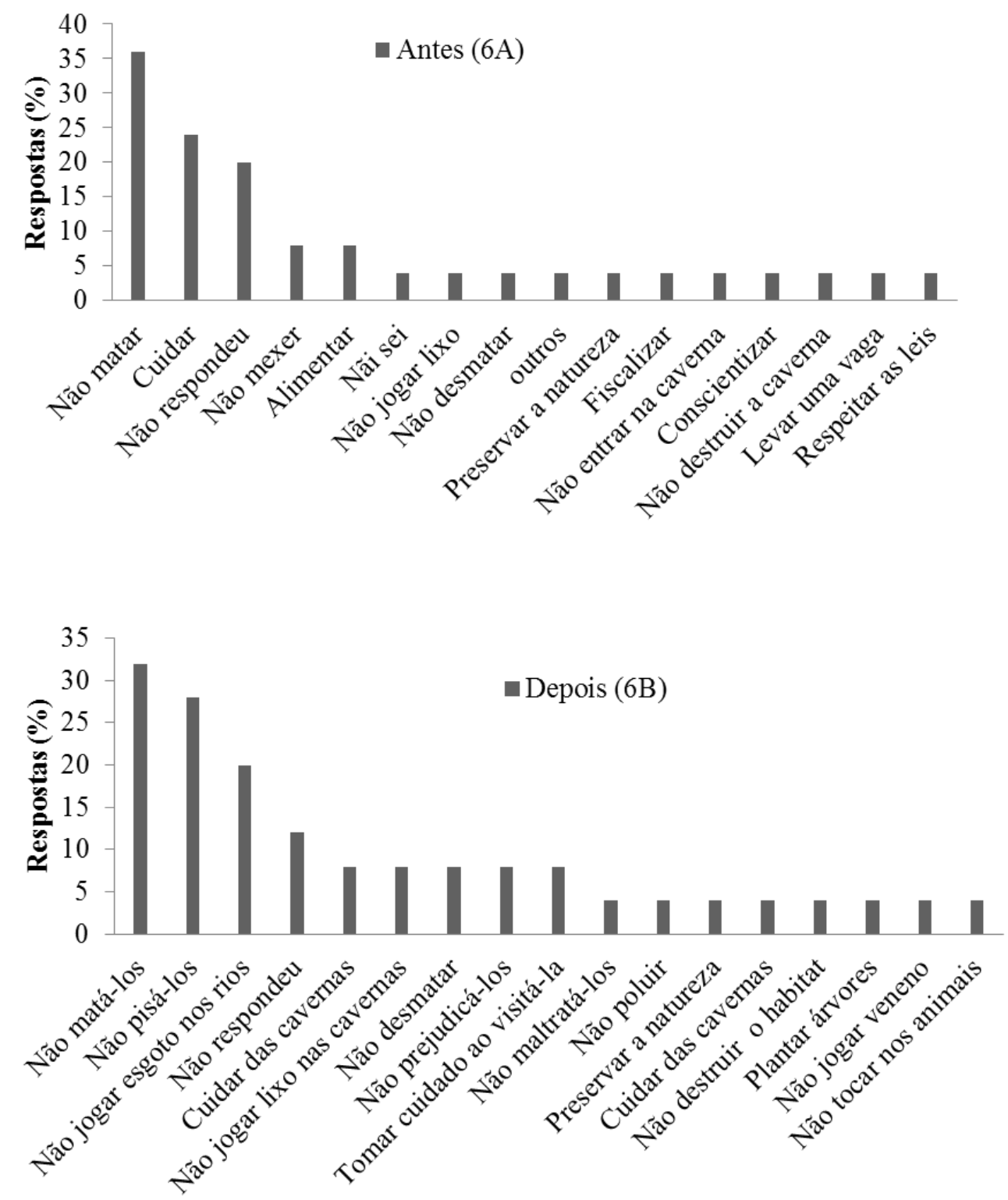

Figura 6. Categorias de respostas construídas com conhecimento informal (antes) e formal (depois), pelos alunos do sexto ano, sobre a preservação de animais de cavernas. (6) Que medidas você tomaria para preservar os animais que vivem nas cavernas? 
Antes da leitura da cartilha, as respostas em relação à sexta pergunta, "Que medida você tomaria para preservar os animais que vivem nas cavernas?", que apresentaram maior freqüência foram não matar (36\%) e cuidar (24\%) (figura 6A). Vinte por cento dos alunos não responderam a esta questão (figura 6A). Após a aplicação da cartilha, as repostas mais frequentes para a questão foram não matá-los (32\%), não pisá-los (28\%) e não jogar esgoto nos rios (20\%) (figura 6B).

\section{4-Discussão}

\section{A CARTILHA COMO FERRAMENTA DE EDUCAÇÃO AMBIENTAL}

A reflexão sobre as práticas sociais, em um contexto marcado pela degradação permanente do meio ambiente, envolve uma necessária articulação com a produção de sentidos sobre a educação ambiental (Jacobi, 2003).

Em tempos onde os meios de divulgação (ciberespaços, multimídias, internet, dentre outros) assumem um papel cada vez mais relevante, a educação para a cidadania representa a possibilidade de motivar e sensibilizar as pessoas para transformar as diversas formas de participação na defesa da qualidade de vida. Nesse sentido, cabe destacar que a educação ambiental assume cada vez mais uma função transformadora, na qual a responsabilização dos indivíduos torna-se um objetivo essencial para promover um novo tipo de desenvolvimento - o desenvolvimento sustentável. O educador tem a função de mediador na construção de referenciais ambientais e deve saber usá-los como instrumentos para o desenvolvimento de uma prática social centrada no conceito da natureza (Morgado et al 1996; Jacobi, 2003).

Neste sentido, ferramentas didáticas voltadas à educação ambiental devem ser facilmente utilizáveis tanto na educação formal quanto informal (Dias, 2004). A educação, a percepção e o lúdico podem ser utilizados para possibilitar a expansão de uma consciência conservacionista, através do envolvimento afetivo das pessoas com a natureza (Neiman \& Rabinovici, 2008).

No Brasil, são poucos os livros textos que tratam de forma mais ampla a divulgação do tema cavernas (Margado et al 1996; Clayton-Lino \& Allievi, 1980; Branco, 2000; Clayton-Lino, 2001; Marra, 2001). Além disto, a carência de profissionais ou técnicos capacitados a exercerem e coordenarem atividades, de forma sustentável, em ambientes cavernícolas é evidente (Ferreira et al 2008).

Considerando a educação ambiental como forma de desenvolvimento de cidadania, a escola referência o conhecimento e a formação, buscando, através de trabalhos educativos e informativos, efeitos conscientes e reflexivos no processo de construção quantitativa e qualitativa de uma educação ambiental. Concentra, assim, o desenvolvimento de projetos que aprimoram e fundamentam questões ambientais em todos os sistemas (Binotto et al 2003). 
Percebe-se que a cartilha ilustrada pode funcionar como um veículo de comunicação, pois resulta em mudança de percepção, mesmo que temporária, sobre as características do ambiente e induz a formação de pessoas com um melhor conhecimento das condições físicas, tróficas, biológicas e de fragilidade destes ambientes.

A falta de conhecimentos básicos, acerca da biologia em geral, dificulta a compreensão e interpretação de questões relacionadas a meio ambiente e vida nas cavernas. Sendo assim, o estudo do meio ambiente no Ensino fundamental e médio deve ser desenvolvido a fim de ajudar os alunos a construírem e ajustarem uma consciência global das questões relativas ao meio, para que possam assumir posições afinadas com os valores referentes a sua proteção e melhoria.

\section{ESPELEOTURISMO COMO FERRAMENTA DE EDUCAÇÃO}

A experiência de visitar uma caverna é descrita como uma atividade que desperta a curiosidade e a sensação de exploração em cada um que se lança neste propósito (Marra, 2001). Apesar dos alunos do sexto ano do ensino fundamental (avaliados neste estudo), residirem bem próximos a uma região com cavernas, evidenciou-se que a escola não utiliza visitas a cavernas como uma prática pedagógica para a educação ambiental. Neste caso especifico a necessidade das práticas de visita a cavernas vai além de contemplar o estudo das cavernas na abordagem do tema meio ambiente, mas trata de um ensino focado na realidade do estudante. Neste caso os temas espeleoturismo, ecologia, fragilidade ambiental, sustentabilidade, recursos hídricos, espeleogênese, espeleotemas e as relações entre cavernas e meio ambientes poderiam ser utilizados como elementos complementares de promoção de interdisciplinaridade e aprendizado com uma alta possibilidade de aplicação na realidade dos estudantes.

Durante a aplicação dos questionários os alunos mostraram interesse verbal em realizar tal prática. Entretanto, a necessidade de professores capacitados, equipamentos básicos de segurança e condução podem infelizmente dificultar tais visitas. Entretanto, em Minas Gerais, algumas cavernas são adaptadas ao turismo de massa sendo o transporte dos alunos e o custo da visitação os principais obstáculos para as escolas. Assim, ausência de práticas pedagógicas e experiências informais podem justificar o pouco conhecimento que os alunos têm sobre as cavernas. Muitas são as atividades práticas fundamentais para o ensino de Ciências, dentre elas visitas técnicas com observações in loco. A possibilidade de que estas atividades de visitas estejam praticamente ausentes no cotidiano da escola é preocupante, principalmente no momento crucial da formação do indivíduo na fundamentação da construção de uma visão científica voltada a entender e explicar as leis, fatos e fenômenos da natureza e com implicações socioambientais (Andrade \& Massabni, 2011; Krasilchik, 2004). 


\section{EDUCAÇÃO EM AMBIENTES DE CAVERNAS COMO UM COMPONENTE DA SUSTENTABILIDADE}

Segundo Van-Beynen e colaboradores (2012) a abordagem do tema educação relacionada nos segmentos formais e não formais, são medidas de sustentabilidade para desenvolvimento de atividades de espeleoturismo. Segundo estes autores, a educação é a abordagem mais eficaz para promover o uso sustentável de paisagens com cavernas em rochas carbonáticas (regiões cársticas). Escolas em uma região cárstica devem oferecer algum tipo de educação relacionada ao carste e ou espeleoturismo.

Além disto, regiões com cavernas turísticas oferecem uma rara oportunidade de educar o público em geral sobre sustentabilidade da paisagem cárstica. Durante as visitas informação científica pode ser transmitida aos turistas, mesmo que em pequena quantidade. Assim, em todas as cavernas turísticas, poderia haver uma inclusão sutil de como podemos melhorar as interações entre as atividades na superfície e ambiente subterrâneo em áreas cársticas. Além disto, agências governamentais devem ter informações em seus sites ou informação escrita disponível para o público em seus escritórios e locais chaves para a divulgação (Van-Beynen et al 2012).

A sensibilização pode ser uma etapa inicial e imprescindível para avançar nos processos da educação ambiental. Entretanto, a ação de sensibilização não produz avanços significativos para uma compreensão mais abrangente da sociedade, nem se refletem em mudanças de atitudes e, muito menos, ajudam a construir uma nova forma de racionalidade ambiental, que consideramos o objetivo final do processo de educação ambiental para o desenvolvimento sustentável (Medina, 2001).

Desta forma, no que concerne a educação, é claramente visível a necessidade de estudos que visem a formulação de materiais e planos para o ensino e divulgação da dinâmica do ambiente de cavernas visando o uso sustentável destas cavidades. O uso de cartilhas ilustradas pode funcionar como uma importante prática educativa uma vez que trazem informações relevantes de forma acessível e bem atrativas para crianças, mas que pode também, pelo menos em parte, ser utilizada na educação de jovens e adultos. Tal prática poderá fornecer à população atividades que articulem seus conhecimentos em conjunto, construindo, em cada um, uma visão ampla deste ambiente e, com isto, despertando o interesse por sua conservação (Kastning \& Kastning, 1999; Lobo, 2006; Silva \& Camargo, 2008; Van-Beynen et al 2012).

\section{CONSIDERAÇÕES FINAIS}

O patrimônio espeleológico pode ser considerado um elemento adicional para o desenvolvimento econômico e social de uma dada região (Santos, 2008). Contudo, ele é extremamente frágil, e explorações intensivas o alteram de forma irreversível. Assim, o elemento ambiental deve ser considerado com o principal suporte na manutenção duradoura das atividades de uso. Mesmo assim, é preciso considerar sua utilização para o desenvolvimento socioeconômico

DOI: Em andamento. 
de certas regiões, cuidando para que o ambiente não seja consumido inutilmente. Sua conservação depende de uma política de uso eficaz que deve considerar, entre outros fatores, a conscientização dos indivíduos envolvidos para que ocorra de forma racional a ocupação territorial pelas instalações turísticas e pelos equipamentos de lazer e o controle do seu crescimento de forma ordenada e integrada a sustentabilidade, visando salvaguardar os recursos para as gerações futuras. Neste contexto a educação ambienta é uma ferramenta chave no desenvolvimento da sustentabilidade.

AGRADECIMENTOS: Alunos e professores que auxiliaram no estudo e ao Centro universitário de Lavras (UNILAVRAS)

\section{Referências Bibliográficas:}

Andrade, M.L.F. \& Massabni, V.G. 2011. O desenvolvimento de atividades práticas na escola: um desafio para os professores de ciências, Ciência \& Educação, v. 17, n. 4, p. 835-854

Binotto, R. F.; Missio, \&. Pires, M. R. S. Educação ambiental nas séries iniciais do ensino fundamental das escolas estaduais e municipais de Frederico Westphalen, Revista de Pesquisa e Pós-Graduação - Santo Ângelo. 2003.

Branco, S. M. O ambiente das cavernas. Editora: Moderna, primeira edição, 48 pp. 2000.

Castro, D.C. \& Bejarano N.R.R. Conhecimentos Prévios sobre Seres Vivos dos Estudantes das Séries Iniciais da Cooperativa de Ensino de Central - COOPEC- BA. Revista Brasileira de Ensino de Ciência e Tecnologia 1(6): 19-40. 2013.

CDRC. Centro de Referência de Reciclagem de Resíduos da Construção Civil e Demolições, http://inac.org.br/crcd1/materiais-utilizados/educacao-ambiental-cartilha/. 2013

Cl. Conservação Internacional, http://www.conservation.org.br/publicacoes/index.php?t=2. 2013

Cigna A.A. \& Forti, P. Caves: the most important geotouristic feature in the world, Tourism and Karst Areas, 6(1):9-26. 2013.

Luiz Marcelo Darroz, M.L., Rosa C,T.W., Rosa A.B. \& Pérez C.A.S. 2013. Mapas conceituais como recurso didático na formação continuada de professores dos primeiros anos do ensino fundamental: um estudo sobre conceitos básicos de astronomia, R. B. E. C. T., 3(6):82-105.

Pelizzari, A., Kriegl, M.L. Baron, M.P., Finck, N.T.L. \& Dorocinski, S.I. 2002. teoria da aprendizagem significativa segundo Ausubel, Rev. PEC, 1(2):37-42.

Dias, G. E. Educação ambiental: princípios e práticas. 2.ed. São Paulo: Editora Gaia. . 2004.

ECOAR. Instituto ECOAR para a cidadania, http://www.ecoar.org.br/web/pag.php?id=32. 2013 
Ferreira, R., L., Gomes, F., T., M. C. \& M., Souza Silva. Uso da cartilha "aventura da vida nas cavernas" como ferramenta de educação nas atividades de turismo em paisagens cársticas, Pesquisas em Turismo e Paisagens Cársticas, 1(2):139-158. 2008.

Figueiredo, L. A. V. Cavernas brasileiras e seu potencial espeleoturistico: um panorama entre a escuridão e as luzes. In Turismo e meio ambiente. Editora Funece, Fortaleza.1998.

GRAFEN. Studios Grafen. http://grafen.com.br/cartilhas-educacao-ambiental/. 2013

IBAMA Instituto Brasileiro do Meio Ambiente e dos Recursos Naturais Renováveis, http://www.ibama.gov.br/supes-es/cartilhas-educativas. 2013.

IPÊ Instituto de Pesquisas Ecológicas. http://www.ipe.org.br/artigos-cientificos/pesquisaeducacao-e-extensao-socioambiental. 2013.

Jacobi, P. Educação ambiental, cidadania e sustentabilidade, Cadernos de Pesquisa, 118:189-205. 2003.

Kastning, E. H. \& Kastning, K., M. Misconceptions about Caves and Karst: Common Problems and Educational Solutions. National Cave and Karst Management Symposium, 99-107. 1999.

Krasilchik, M. Prática de ensino de biologia. Editora da Universidade de São Paulo, v. 1. 197 pp. 2004.

Lecastres E. F. Impressos em programas para gestante cardíaca, Tese de Doutorado da Faculdade de Saúde Pública da USP, São Paulo, SP. 1986.

Lino F. \& J. Allievi Cavernas Brasileiras. 168pp. Editora melhoramentos LTDA. São Paulo. 1980.

Lino F. Cavernas; O fascinante Brasil subterrâneo. 288pp. Editora Gaia LTDA. São Paulo. 2001.

Lobo, H. A. S. O lado escuro do paraíso espeleoturismo na Serra da Bodoquena, MS. Aquidauana, UFMG/CEUA, Dissertação de mestrado. 2006.

Maia-Barbosa, P., M., Alonso, R., S. \& F., E., C. Viana. Aprendendo ecologia através de cartilhas, Anais do 70 Encontro de Extensão da Universidade Federal de Minas Gerais Belo Horizonte - 12 a 15 de setembro de 2004, PP 1-6. 2004.

Marra, R. J. C. Espeleoturismo: planejamento e manejo de cavernas, Editora W. D. Ambiental, 224 pp. 2001

MEC. Secretaria de educação fundamental. Parâmetros Curriculares Nacionais: terceiro e quarto ciclos do ensino fundamental. Temas transversais. Brasília: MEC/SEF, 436p. 1998

Medina, N. M. Panorama da educação ambiental no ensino fundamental / Secretaria de Educação Fundamental - Brasília :MEC ; SEF,.149 pp. 2001.

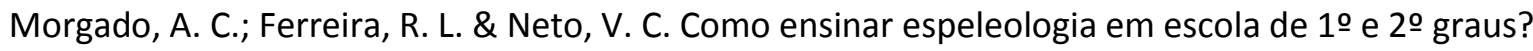
O carste. 3 (8) 65. 1996.

R. B. E. C. T., vol 7, núm. 3, set-dez.2014 ISSN - 1982-873X

DOI: Em andamento. 
Neiman, Z. \& Rabinovici, A. Espeleoturismo e educação ambiental no PETAR - SP, Pesquisas em Turismo e Paisagens Cársticas, 1(1): 57-65. 2008.

Reigota, M. Desafios à educação ambiental escolar. In: JACOBI, P. et al. (orgs.). Educação, meio ambiente e cidadania: reflexões e experiências. São Paulo: SMA, 1998. p.43-50. 1998.

Santos R.A. Espeleoturismo na caverna Lapa Doce: potencialidades para um turismo sustentável no município de Iraquara - Bahia. Pesquisas em Turismo e Paisagens Cársticas, 1(2):131-144. 2008.

Santos, S. O. Princípios e técnicas de comunicação: in Educação Ambiental e sustentabilidade, Arlindo Philippi Jr., Maria Cecília Focesi Pelicioni editores, Editora Manole Ltda. 878 pp.São Paulo: Ipê,. 2005.

Silva, L. F. \& R. R., Camargo. Valoração econômica das cavernas da microbacia do rio salobra, Bodoquena-MS como subsídio ao planejamento ecoturístico, Pesquisas em Turismo e Paisagens Cársticas, 1(2):121-129. 2008.

Van-Beynen P, Brinkmann, R., Van Beynen K. A sustainability index for karst environments. Journal of Cave and Karst Studies, 2(74): 221-234. 2012

Ward. A. The use of posters and leaflets in a specialist health education department. Health Educ J. 1(41):17-20. 1982.

Marconi Souza Silva, Universidade Federal de Lavras, Departamento de Biologia, Setor de Zoologia Geral, Centro de Estudos em Biologia Subterrânea - CEBS/UFLA (www.biologiasubterranea.com.br), marconisilva@dbi.ufla.br

Rodrigo Lopes Ferreira, Universidade Federal de Lavras, Departamento de Biologia, Setor de Zoologia Geral, Centro de Estudos em Biologia Subterrânea - CEBS/UFLA.

Roberta Correa Damasceno - Centro Universitário de Lavras - UNILAVRAS 